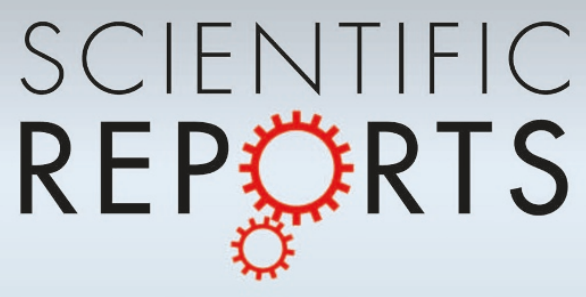

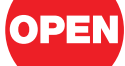

SUBJECT AREAS:

POLYMERS

POLYMER SYNTHESIS

SOFT MATERIALS

MECHANICAL PROPERTIES

Received

25 July 2012

Accepted

6 December 2012

Published

21 January 2013

Correspondence and requests for materials should be addressed to A.J.Q. (qinaj@zju.edu. cn) or B.Z.T.

(tangbenz@ust.hk)

\section{Self-healing hyperbranched poly(aroyltriazole)s}

\author{
Qiang Wei', Jian Wang' 'Xiaoyuan Shen' 'Xiao A. Zhang' , Jing Zhi Sun' , Anjun Qin' \& Ben Zhong Tang', 2
}

${ }^{1}$ MOE Key Laboratory of Macromolecular Synthesis and Functionalization, Department of Polymer Science and Engineering, Zhejiang University, Hangzhou 310027 , China, ${ }^{2}$ Department of Chemistry, Institute for Advanced Study, Institute of Molecular Functional Materials, State Key Laboratory of Molecular Neuroscience, and Division of Biomedical Engineering, The Hong Kong University of Science \& Technology, Clear Water Bay, Kowloon, Hong Kong, China.

The research on self-healing polymers has been a hot topic. The encapsulated-monomer/catalyst, supramolecular self-assembly, and reversible or dynamic covalent bond formation are the prevailingly adopted strategies. The alternative of irreversible covalent bond formation is, however, to be further developed. In this contribution, self-healing hyperbranched poly(aroyltriazole)s of PI and PII sharing such mechanism were developed. The polymers were synthesized by our developed metal-free click polymerizations of bis(aroylacetylene)s and triazide. They are processible and have excellent film-forming ability. High quality homogeneous films and sticks free from defects could be obtained by casting. The scratched films could be self-repaired upon general heating. The cut films and sticks could be healed by stacking or pressing the halves together at elevated temperature. Thus, these hyperbranched polymers could find broad applications in diverse areas, and our design concept for self-healing materials should be generally applicable to other hyperbranched polymers with reactive groups on their peripheries.

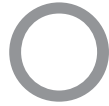

ne of the nature's most remarkable features is the ability to recover itself, i.e. self-healing, upon damage, such as cuts or bruises ${ }^{1}$. Inspired by the nature, researchers have designed and developed various materials with self-healing property ${ }^{2}$, among which, polymeric materials are by far the most studied probably due to their ease to functionalize and modify ${ }^{3-8}$. In general, the repairing mechanism of healable polymers could be divided into two classes differentiated by whether an external stimulus is needed ${ }^{9}$. One is an autonomic self-healing process that requires no triggers except the damage, whereas, the other is nonautonomic amendment, which is responsive to a specific external stimulus, such as light and heat.

With the enthusiastic efforts paid by the polymer chemists, significant progress has been made in aforementioned classes, but the researches on the self-healing approaches were mainly focused on the encapsulatedmonomer/catalyst ${ }^{10-16}$, supramolecular self-assembly ${ }^{17-25}$, and reversible or dynamic covalent bond formation ${ }^{26-}$ ${ }^{34}$. Among these developed approaches, the first two possess limited mechanical properties with stress generally less than $10 \mathrm{MPa}$, and the latter could decrease its mechanical property at elevated temperature. For example, materials healed via the Diels-Alder (DA) chemistry will suffer from the dissociation of covalent bonds via the retroDA reaction at temperature high than $120^{\circ} \mathrm{C}^{35}$. Alternatively, the irreversible covalent bond formation will be an ideal strategy to repair the damage and enhance the mechanical property of a polymeric material simultaneously. This approach, however, need to be further developed ${ }^{9,36-38}$. Moreover, in the reported systems, multiple components are needed, which will complicate the manipulation procedures. For example, Urban and coworker have reported a photo-healable irreversible covalent-bonded heterogeneous polyurethane networks based on oxetane-substituted derivative of chitosan, which could not formed without addition of the components of hexamethylene diisocyanted and polyethylene glycol ${ }^{36,37}$. Du Prez and coworkers have developed autonomous self-healing epoxy materials, in which the crack area should fill with multifunctional thiols and difunctional maleimides to realize the recovery ${ }^{38}$. To simplify the operation and to be practically applicable, the irreversible covalent bonded polymeric material systems that could be healed without any additive will be an exciting research topic.

Our ongoing research projects have shone the light into this emerging area. We have been interested in the construction of new macromolecules using alkyne monomer building blocks and have synthesized a variety of polymers with linear and topological structures ${ }^{39}$. Because of the key role of alkynes in the alkyne-azide click reactions $^{40,41}$ and as a natural extension of our alkyne-based research program, we have embarked on the syntheses of functional polytriazoles and successfully developed this organic reaction into to powerful click polymerization ${ }^{42,43}$. During the cause of development of the $\mathrm{Cu}(\mathrm{I})$-catalyzed azide-alkyne click reaction into a polymerization technique, we have also successfully established metal-free click polymerizations (MFCPs) of 


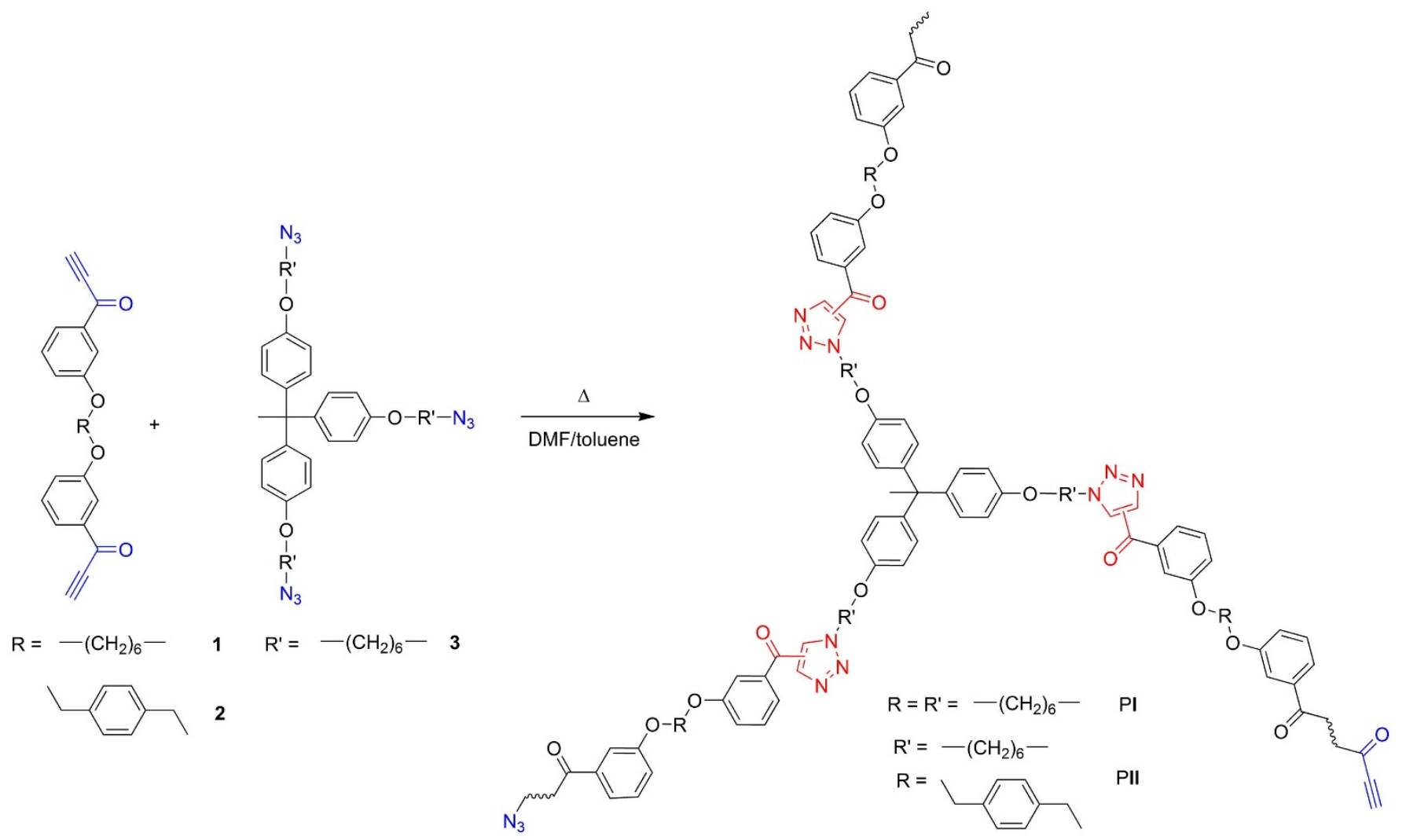

Figure 1 Synthetic routes to hyperbranched poly(arolytriazole)s of PI and PII.

azides and activated alkynes ${ }^{42-47}$. For example, the polymerizations of aroylacetylenes and azides under mild reaction conditions produced functional linear poly(aroyltriazole)s (PATAs) with high molecular weights and regioregularities in high yields. No hyperbranched PATA ( $h b$-PATA), however, has been prepared by this powerful polymerization technique. The $h b$-PATAs are expected to show unique properties due to their topological global structures ${ }^{48}$, and the remaining tremendous reactive azide and aroylacetylene groups on the periphery makes $h b$-PATAs promising candidates to be developed into simple self-healing systems ${ }^{49}$.

Though the alkyne-azide click reactions have been used to prepare self-healing polymers, the focus was on the $\mathrm{Cu}(\mathrm{I})$-catalyzed systems $\mathrm{s}^{50-54}$, which are heterogeneous due to the catalyst additives and make the healing process complicated. For example, Binder and coworkers have applied this reaction to prepare self-healing polymers but with the encapsulated-monomer strategy ${ }^{50,51}$. In this contribution, we report an irreversible covalent-bonded self-healing system based on $h b$-PATAs. Thanks to the metal-free feature and the remaining azide and aroylacetylene groups on their periphery, the bulky materials of $h b$-PATAs are homogeneous and could be healed without any additive, which will greatly simplify the healing manipulation and facilitate the practical application.

\section{Results}

Preparation of $\boldsymbol{h} \boldsymbol{b}$-PATAs. These polymers were synthesized by our developed alkyne-azide MFCP as shown in Figure 1. To facilitate monomers preparation and to avoid monomer oligomerization during their storage, we adopted a dialkyne $\left(\mathrm{A}_{2}\right)+$ triazide $\left(\mathrm{B}_{3}\right)$ strategy to prepare the $h b$-PATAs. Bis(aroylacetylene)s (1 and 2$)^{55}$ and triazide $(3)^{56}$ were thus designed and synthesized according to our previous published methods. By investigating the MFCP conditions using monomers $\mathbf{2}$ and $\mathbf{3}$, such as reaction temperature, monomer concentration (Supplementary Tables S1 and S2), the optimal ones were obtained. When bis(aroylacetylene)s (concentration: $0.18 \mathrm{M}$ ) polymerized with triazide (concentration: $0.12 \mathrm{M}$ ) in $\mathrm{DMF} /$ toluene $\left(1: 1\right.$ by volume) at $70^{\circ} \mathrm{C}$ for $6 \mathrm{~h}$ under nitrogen, $h b$ PATAs of PI and PII with high molecular weights (up to 27,800 g $\mathrm{mol}^{-1}$ ) were obtained in excellent yields (up to 97.6\%) (Fig. 1). Most importantly, the polymers are soluble in common used organic solvents, such as chloroform, dichloromethane, tetrahydrofuran. Moreover, they are still soluble even after two weeks' storage at $-19^{\circ} \mathrm{C}$ because this temperature could greatly lower the reactivity of azide and alkynes groups. The synthesized polymers are thermally
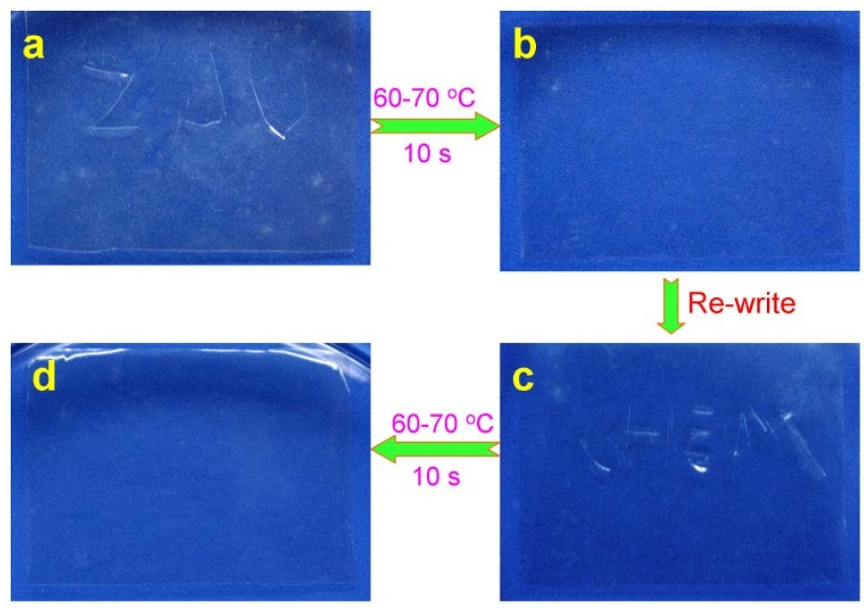

Figure $2 \mid$ Self-repairing of the scratched surface of PI film. (a) Curved "ZJU" on the surface, (b) after heating the film, (c) re-inscribed "CHEM" on the same place of the surface, and (e) recovered surface of the film again by the same method. To better visualize the process, a blue background was used. The film is in the size of $19.9 \mathrm{~mm} \times 26.3 \mathrm{~mm}$. 

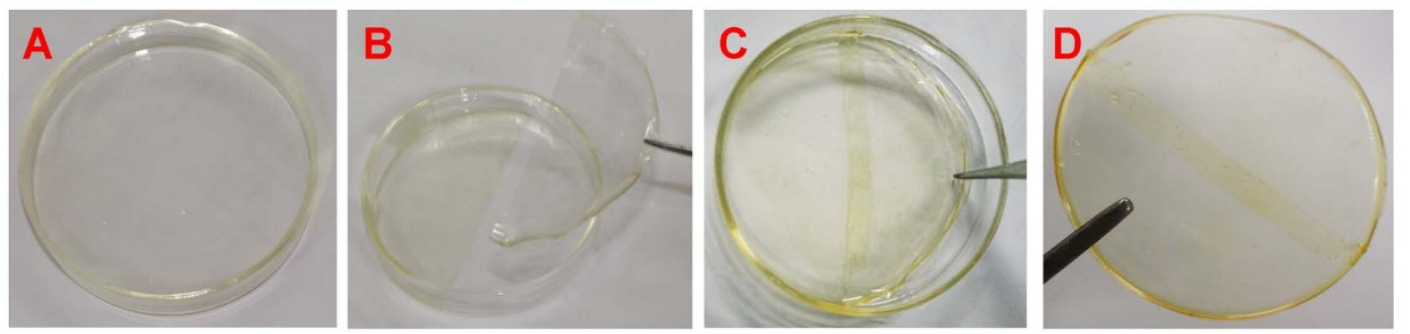

Figure 3 Self-healing on the surface of PI film. (a) the as-prepared film from PI in petri-dish; (b) the half-cut film by a razor blade; (c) the self-healed film with overlapping width of $5 \mathrm{~mm}$ after heated at $110^{\circ} \mathrm{C}$ for $4 \mathrm{~h}$; (d) the self-healed and stripped film. The diameter of petri-dish is $60 \mathrm{~mm}$, the thickness of the as-prepared film is $45 \pm 10 \mu \mathrm{m}$.

stable. As could be seen from the thermogravimetric analysis (TGA) curves shown in Supplementary Figure S1, PI and PII show high resistance to thermolysis and lose $5 \%$ of their weights at temperatures of 361 and $363^{\circ} \mathrm{C}$, respectively.

Thanks to their good solubility, the polymer structures were fully characterized by IR, and ${ }^{1} \mathrm{H}$ and ${ }^{13} \mathrm{C}$ NMR spectra (Supplementary Figs. S2-S7). Satisfactory analysis results corresponding to their structures were obtained. From the spectra, we could conclude that azide and alkyne groups are remained in the obtained $h b$-PATAs. The fractions of 1,4-disubstituted 1,2,3-triazoles of PI and PII could be calculated from the ${ }^{1} \mathrm{H}$ NMR spectra according to our previous methods ${ }^{44}$, which are 91.7 and $90.9 \%$, respectively. It is worthy noting that these values are pretty higher that that of their linear analogues $(<89.3 \%)^{44,45}$, probably due to the branched structures and lower reaction temperature.

Self-repairing of the scratched surface of polymer film. Unlike traditional hyperbranched polymers, PI and PII feature excellent film-forming abilities, which enable us to prepare self-standing and transparent homogeneous thick films with ease. Interestingly, the surface of dried polymer films could be recovered from damage of scratch. The curved letters of "ZJU" (Fig. 2a) on the surface of PI film could completely disappear upon heating at $60-70^{\circ} \mathrm{C}$ for $10 \mathrm{~s}$ under ambient conditions (Fig. 2b). Furthermore, the re-inscribed "CHEM" on the same place (Fig. 2c) could be resumed without any mark by the same method (Fig. 2d). To have the detailed information about the effect of temperature on the re-pairing process, the film was tested in a water bath with tunable and controllable temperature. The results showed that it took 100-120 s to resume the curved surface at $50^{\circ} \mathrm{C}$ but $\sim 10 \mathrm{~s}$ at $60^{\circ} \mathrm{C}$. More importantly, this self-repairing process was repeatable during our test. The similar behaviors were observed for PII films.

To get insight into the intrinsic mechanism of the self-repairing feature of the polymer films, differential scanning calorimetry (DSC) measurements were carried out (Supplementary Fig. S8). The results showed that the glass transition temperatures $\left(T_{\mathrm{g}}\right)$ of PI and PII are 59.5 and $69.3^{\circ} \mathrm{C}$ in the second heating cycle, respectively. Thus, heating the polymer film above its $T_{\mathrm{g}}$ allowed the material to reflow and repair. Once the film was cooled below the $T_{\mathrm{g}}$, it regained gloss and hardness ${ }^{35}$. Furthermore, with increasing heating cycles from 2 nd to 5th, the $T_{\mathrm{g}} \mathrm{s}$ for PI and PII are enhanced only for 9.1 and $20.4^{\circ} \mathrm{C}$, indicating that short time heating of the films impart little effect on their thermal properties and the cross-linking effect plays an ignorable role during the process. These results also well explain the repeatability of the self-repairing of the film surfaces.

Self-healing of the polymer films. Thanks to the good film-forming ability of $h b$-PATAs, perfect films with thickness of $45 \pm 10 \mu \mathrm{m}$ could be fabricated by casting (Fig. 3). From the FT-IR attenuated total reflectance (ATR) spectra of the as prepared films of PI and PII (Supplementary Fig. S9), we still could found the vibration bands of azide and alkyne at $2100 \mathrm{~cm}^{-1}$, with provide a good chance for us to use them to perform the self-healing experiments. As shown in Figure 3, the dried film of PI was first halved by a razor blade, then part of it was peeled off from the petri-dish, stacked to another with overlapping length of $5 \mathrm{~mm}$, and heated at $110^{\circ} \mathrm{C}$. The results showed that after heating at this temperature for only $8 \mathrm{~min}$, the stacked film could resume the mechanical strength and bear a clip with a weight of $6.40 \mathrm{~g}$ (Supplementary Fig. S10). To ensure sufficient reaction between azide and aroylacetylene groups on the stacked film surfaces and to fully resume the mechanical property, we extended the healing time to $4 \mathrm{~h}$. As shown in Figure 3d, the healed film could be peeled off from the petri-dish, which enables us to assess its mechanical property by standard methods.

The healed film was cut into several small testing samples with size of 4-5 $\mathrm{mm}$ in width and $40-50 \mathrm{~mm}$ in length. As shown in Figure 4 and Supplementary Figure S11, the Young's modulus and the fracture stress of healed stacked films (PI: 1.2 GPa and 36.9 MPa, PII: $1.5 \mathrm{GPa}$ and $47.4 \mathrm{GPa}$, respectively) are much higher than that of the as-prepared (PI: $0.8 \mathrm{GPa}$ and $28.9 \mathrm{MPa}$, PII: $1.0 \mathrm{GPa}$ and $29.1 \mathrm{MPa}$, respectively) and heated films (PI: $0.9 \mathrm{GPa}$ and $32.8 \mathrm{MPa}$, PII: $1.1 \mathrm{GPa}$ and $42.7 \mathrm{MPa}$, respectively), indicating that the selfhealing process could reinforce the mechanical property of the film

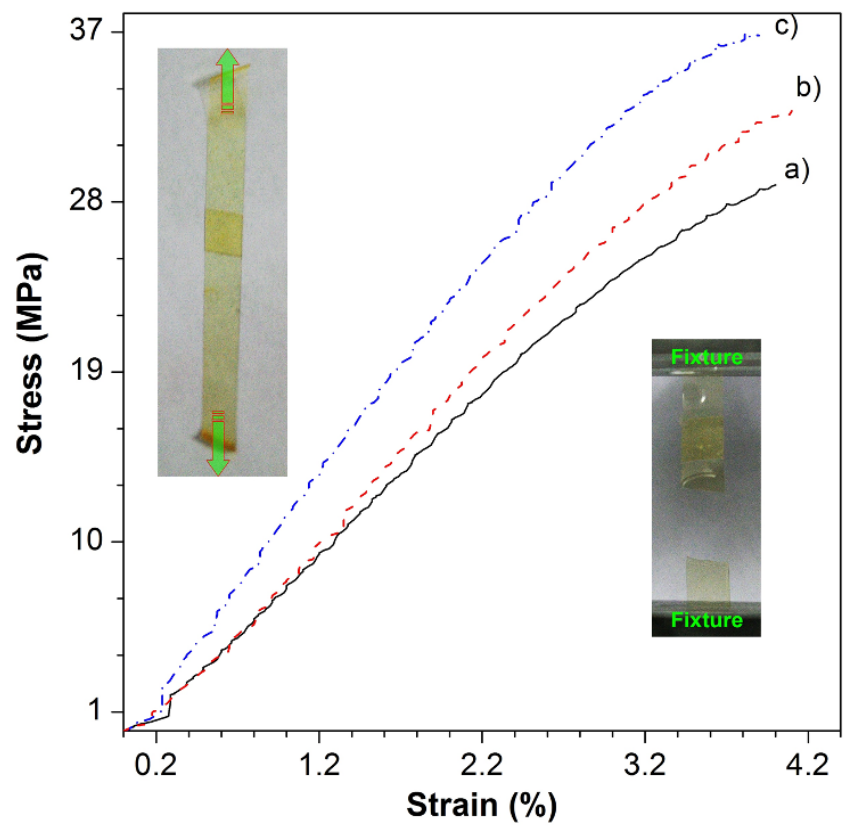

Figure 4 Stress-strain curves of PI films. (a) The as-prepared film without curing, (b) the pristine film after heating at $110^{\circ} \mathrm{C}$ for $4 \mathrm{~h}$, and (c) the self-healed film. The test was carried out at room temperature with humidity of $52 \%$ at a pulling rate of $2 \mathrm{~mm} \mathrm{~min}^{-1}$ by Reger-RWT10 instrument with the standard length of $20 \mathrm{~mm}$. The samples were $4-5 \mathrm{~mm}$ in width. Inset: the healed film sample and the force direction as well as the broken site of the film after test. 

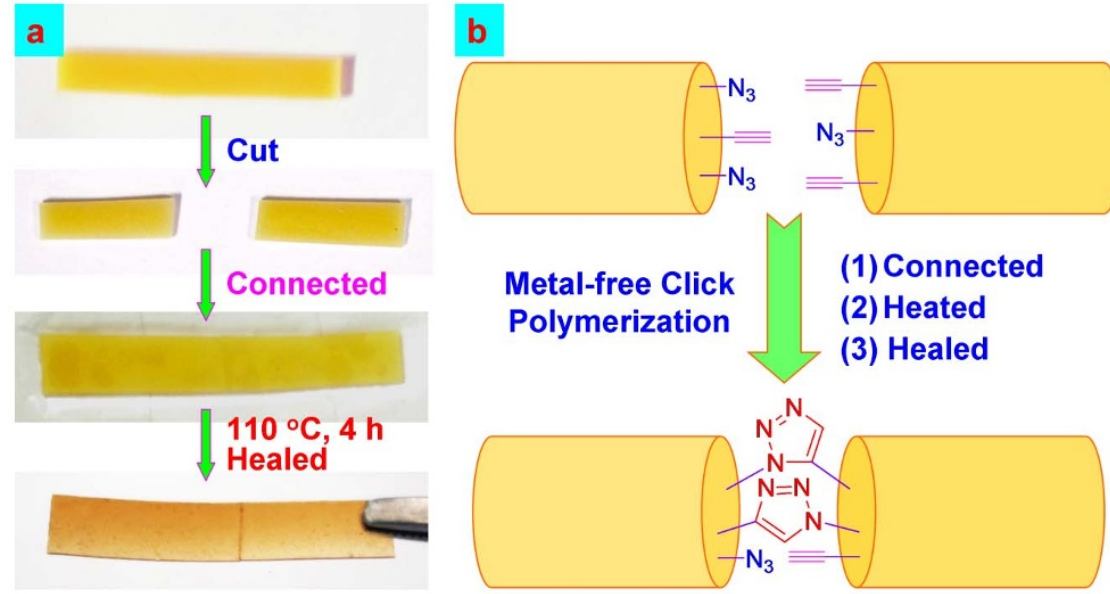

Figure $5 \mid$ (a) The self-healing process of the PI sticks, and (b) the proposed mechanism of self-healing of polymer sticks. The sizes of the sticks are $4.10 \mathrm{~mm}$ in width, $1.06 \mathrm{~mm}$ in thickness, and $27 \mathrm{~mm}$ in length.

simultaneously. Furthermore, the broken site was near the fixture of the testing machine instead of the healed area, revealing that the healed area has stronger mechanical property. The healed stacked film was further investigated by IR spectroscopy. The weakened absorption bands of azide and alkyne groups at $2096 \mathrm{~cm}^{-1}$ of healed films manifested that part of remaining azide and aroylacetylenes have been reacted to form aroyltriazole cross-linked network according to our previous findings (Supplementary Fig. S12) (4,45. $^{4}$. Furthermore, the left azide and alkyne groups in the healed films could be further reacted upon heating, which proves a possibility for the films to be healed again upon broken.

Self-healing of the polymer sticks. The PI and PII could not only be casted into thick films but also be fabricated into homogeneous sticks free from defects. We thus used the polymer sticks to investigate their self-healing behaviors. The dried sticks with sizes of $4.10 \mathrm{~mm}$ in width, $1.06 \mathrm{~mm}$ in thickness, and $27 \mathrm{~mm}$ in length were cut into two halves, which were pressed together and heated at $110^{\circ} \mathrm{C}$ for $4 \mathrm{~h}$ (Fig. 5a). Then, the self-healing process was activated and the halves were re-connected to form a healed stick. The self-healing could be attributed to the cross-linking reactions between the remaining azides and aroylacetylene groups on the cut surfaces as demonstrated in Figure 5b.

The mechanical property of as-prepared and healed sticks was investigated by standard methods. As shown in Figure 6, the sticks could sustain a deformation when imparting pulling force vertical to the healed surfaces. The stress (13.5 MPa) and Young's modulus (94.7 MPa) of the self-healed stick are 2.5 and 14.6 times higher than that of the pristine one, respectively, indicating that the self-healing process could remarkably enhanced the mechanical property of sticks. It is worthy noting that similar to the healed film, the fracture did not occur along the healed seam, further substantiating the high mechanical strength of healed sticks.

\section{Discussion}

The self-healing polymers may significantly extend the working life and lower production costs, thus, have many general applications in diverse areas. Currently, the research on self-healing polymers has been mainly focused on the encapsulated-monomer/catalyst, supramolecular self-assembly, and reversible covalent bond systems. The irreversible covalent bonded system could realize the self-healing and enhance the mechanical property especially at elevated temperatures simultaneously, but need to be further developed.

In this contribution, we succeeded for the first time in synthesizing processible $h b$-PATAs by MFCPs of aroylacetylenes and azide. The obtained $h b$-PATAs possess excellent film-forming ability and could be fabricated into transparent and homogeneous thick films free from defects by casting. The films are scratch-resisted and the scratch on their film surfaces could be repeatedly repaired by heating at $60-$ $70^{\circ} \mathrm{C}$, making them promising for application in re-writable papers and data storage areas as well as advanced scratch-resisted coatings.

Taking advantage of the remaining azide and aroylacetylene groups on the periphery of $h b$-PATAs, the cut halves of their films and sticks could be healed by stacking or pressing together with general heating at $110^{\circ} \mathrm{C}$ for $4 \mathrm{~h}$. Furthermore, the self-healed materials show higher mechanical strength than their original films or sticks. This irreversible covalent-bonded self-healing system does not need add other component, such as a catalyst, a cross-linker, and could be simply triggered by heating, which enables them to find wide applications in diverse areas. Thus, we believe that our design concept for self-healing materials should be generally applicable to other hyperbranched polymers with reactive groups on their peripheries.

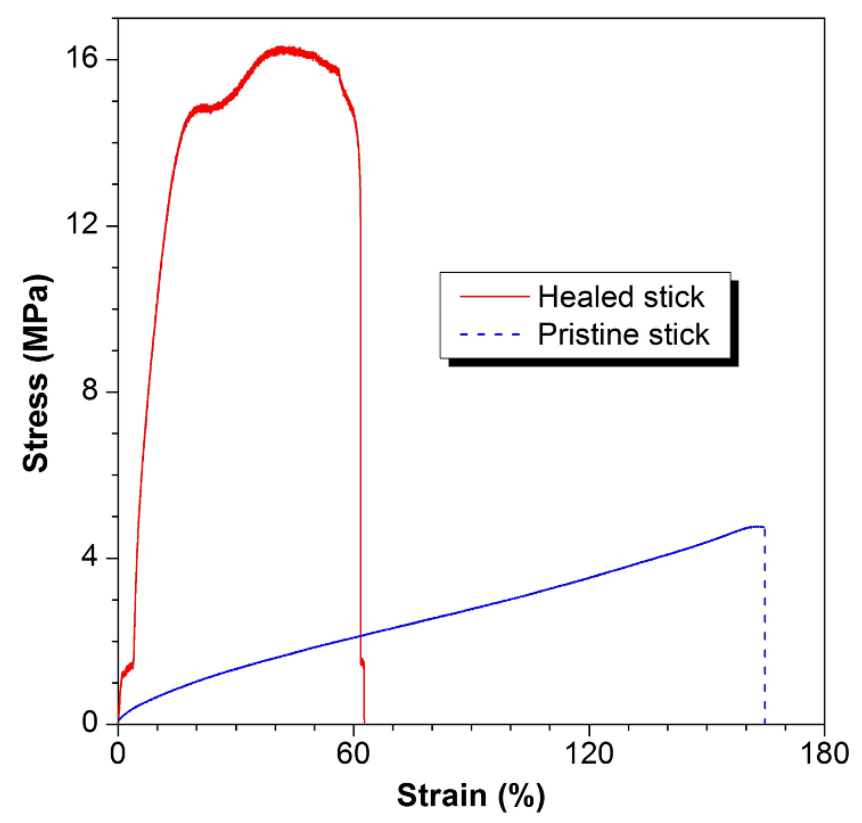

Figure 6 | Stress-strain curves of PI sticks. (a) Before and (b) after selfhealing at $110^{\circ} \mathrm{C}$ for $4 \mathrm{~h}$. The test was carried out at room temperature with humidity of $52 \%$ at a pulling rate of $2 \mathrm{~mm} \mathrm{~min}^{-1}$ by SANS CMT 4204 instrument with the standard length of $20 \mathrm{~mm}$. The sizes of the sticks are $4.10 \mathrm{~mm}$ in width, $1.06 \mathrm{~mm}$ in thickness, and $27 \mathrm{~mm}$ in length. 


\section{Method}

The optimization of MFCP conditions and preparation of $h b$-PATAs are given in supporting information.

Preparation of $\boldsymbol{h} \boldsymbol{b}$-PATA films. The $h b$-PATAs films were prepared by solution casting method. $297 \mathrm{mg}$ of PI or $305 \mathrm{mg}$ of PII were dissolved in $15 \mathrm{~mL}$ 1,2-dichlorethane. The solution was poured into a flat-bottomed glass petri-dish with diameter of $60 \mathrm{~mm}$ and allowed to dry at room temperature for $24 \mathrm{~h}$. Then, the films were further dried at $40^{\circ} \mathrm{C}$ overnight to remove residual solvents.

Fabrication of $\boldsymbol{h} \boldsymbol{b}$-PATA sticks. $1.78 \mathrm{~g}$ of PI was dissolved in $50 \mathrm{~mL} \mathrm{1,2-}$ dichlorethane. The solution was poured into a semi-cylinder glass mode with sizes of $40 \mathrm{~mm}$ in diameter and $100 \mathrm{~mm}$ in length. The dry procedures are same to that of the films. The sticks were obtained by vertically cut the sample.

Mechanical property measurement. The test was carried out at room temperature with humidity of $52 \%$ at a pulling rate of $2 \mathrm{~mm} \mathrm{~min}^{-1}$ by Reger-RWT10 instrument with the standard length of $20 \mathrm{~mm}$. The sticks were tested by SANS CMT 4204 instrument with same experimental conditions.

1. Syrett, J. A., Becer, C. R. \& Haddleton, D. M. Self-healing and self-mendable polymers. Polym. Chem. 1, 978-987 (2010).

2. Hager, M. D., Greil, P., Leyens, C., van der Zwaag, S. \& Schubert, U. S. Self-healing materials. Adv. Mater. 22, 5424-5430 (2010).

3. Murphy, E. B. \& Wudl, F. The world of smart healable materials. Prog. Polym. Sci. 35, 223-251 (2010).

4. Urban, M. W. Stratification, stimuli-responsiveness, self-healing, and signaling in polymer networks. Prog. Polym. Sci. 34, 679-687 (2009).

5. Wu, D. Y., Meure, S. \& Solomon, D. Self-healing polymeric materials: a review of recent developments. Prog. Polym. Sci. 33, 479-522 (2008).

6. Wool, R. P. Self-healing materials: a review. Soft Matter 4, 400-418 (2008).

7. Yuan, Y. C., Yin, T., Rong, M. Z. \& Zhang, M. Q. Self-healing in polymers and polymer composites. Concepts, realization and outlook: a review. Express Polym. Lett. 2, 238-250 (2008).

8. Mauldin, T. C. \& Kessler, M. R. Self-healing polymers and composites. Int. Mater. Rev. 55, 317-346 (2010)

9. Burattini, S., Greenland, B. W., Chappell, D., Colquhoun, H. M. \& Hayes, W. Healable polymeric materials: a tutorial review. Chem. Soc. Rev. 39, 1973-1985 (2010).

10. White, S. R. et al. Autonomic healing of polymer composites. Nature 409, 794-797 (2001).

11. Odom, S. A. et al. A Self-healing Conductive Ink. Adv. Mater. 24, 2578-2581 (2012).

12. Toohey, K. S., Sottos, N. R., Lewis, J. A., Moore, J. S. \& White, S. R. Self-healing materials with microvascular networks. Nat. Mater. 6, 581-585 (2007).

13. Piermattei, A., Karthikeyan, S. \& Sijbesma, R. P. Activating catalysts with mechanical force. Nat. Chem. 1, 133-137 (2009).

14. Cho, S. H., White, S. R. \& Braun, P. V. Self-healing polymer coatings. Adv. Mater. 21, 645-649 (2009)

15. Esser-Kahn, A. P., Odom, S. A., Sottos, N. R., White, S. R. \& Moore, J. S. Triggered Release from Polymer Capsules. Macromolecules 44, 5539-5553 (2011).

16. Mauldin, T. C. \& Kessler, M. R. Enhanced bulk catalyst dissolution for self-healing materials. J. Mater. Chem. 20, 4198-4206 (2010).

17. Cordier, P., Tournilhac, F., Soulie-Ziakovic, C. \& Leibler, L. Self-healing and thermoreversible rubber from supramolecular assembly. Nature 451, 977-980 (2008).

18. Wang, X., Liu, F., Zheng, X. \& Sun, J. Water-enabled self-healing of polyelectrolyte multilayer coatings. Angew. Chem. Int. Ed. 50, 11378-11381 (2011).

19. Nakahat, M., Takashima, Y., Yamaguchi, H. \& Harada, A. Redox-responsive selfhealing materials formed from host-guest polymers. Nat Commun. 2, 511, DOI:10.1038/ncomms1521 (2011).

20. Burnworth, M. et al. Optically healable supramolecular polymers. Nature 472, 334-337 (2011).

21. Zhang, M. et al. Self-healing supramolecular gels formed by crown ether based host-guest interactions. Angew. Chem. Int. Ed. 51, 7011-7015 (2012).

22. Wilson, G. O., Caruso, M. M., Schelkopt, S. R., Sottos, N. R., White, S. R. \& Moore, J. S. Adhesion promotion via noncovalent interactions in self-healing polymers. ACS Appl. Mater. Interfaces 3, 3072-3077 (2011).

23. Aida, T., Meijer, E. W. \& Stupp, S. I. Functional supramolecular polymers. Science 335, 813-817 (2012).

24. Chen, Y., Kushner, A. M., Williams, G. A. \& Guan, Z. Multiphase design of autonomic self-healing thermoplastic elastomers. Nat. Chem. 4, 467-472 (2012).

25. Deng, G. H., Tang, C. M., Li, F. Y., Jiang, H. F. \& Chen, Y. M. Covalent cross-linked polymer gels with reversible sol-gel transition and self-healing properties. Macromolecules 43, 1191-1194 (2010).

26. Chen, X. et al. Thermally re-mendable cross-linked polymeric material. Science 295, 1698-1702 (2002).

27. Yuan, C., Rong, M. Z., Zhang, M. Q., Zhang, Z. P. \& Yuan, Y. C. Self-healing of polymers via synchronous covalent bond fission/radical recombination. Chem. Mater. 23, 5076-5081 (2011).

28. Deng, G. et al. Dynamic hydrogels with an environmental adaptive self-healing ability and dual responsive sol-gel transitions. ACS Macro Lett. 1, 275-279 (2012).
29. Wojtechki, R. J., Meador, M. A. \& Rowan, S. J. Using the dynamic bond to access macroscopically responsive structurally dynamic polymers. Nat. Mater. 10, 14-27 (2011).

30. Zhang, J. et al. Self-healable and recyclable triple-shape PPDO-PTMEG conetwork constructed through thermoreversible Diels-Alder reaction. Polym. Chem. 3, 1390-1393 (2012).

31. Amamoto, Y., Kamada, J., Otsuka, H., Takahara, A. \& Matyjaszewski, K. Repeatable photoinduced self-healing of covalently cross-linked polymer through reshuffling of trithiocarbonate units. Angew. Chem. Int. Ed 50, 1660-1663 (2011).

32. Amamoto, Y., Otsuka, H., Takahara, A. \& Matyjaszewski, K. Self-healing of covalently cross-linked polymers by reshuffling thiuram disulfide moieties in air under visible light. Adv. Mater. 24, 3975-3980 (2012).

33. Lu, Y.-X. \& Guan, Z. Olefin metathesis for effective polymer healing via dynamic exchange of strong carbon-carbon double bonds. J. Am. Chem. Soc. 134, 14226-14231 (2012)

34. Zheng, P. \& McCarthy, T. J. A Surprise from 1954: siloxane equilibration is a simple, robust, and obvious polymer self-healing mechanism. J. Am. Chem. Soc. 124, 2024-2027 (2012)

35. Guimard, N. K., Oehlenschlaeger, K. K., Zhou, J., Hilf, S., Schmidt, F. G. \& Barner Kowollik, C. Current Trends in the field of self-healing materials. Macromol. Chem. Phys. 213, 131-143 (2012).

36. Ghosh, B. \& Urban, M. W. Self-repairing oxetane-substituted chitosan polyurethane networks. Science 323, 1458-1458 (2009).

37. Ghosh, B., Chellappan, K. V. \& Urban, M. W. Self-healing inside a scratch of oxetane-substituted chitosan-polyurethane (OXE-CHI-PUR) networks. J. Mater. Chem. 21, 14473-14486 (2011).

38. Billiet, S., Camp, W. V., Hillewaere, X. K. D., Rahier, H. \& Du Prez, F. E. Development of optimized autonomous self-healing systems for expoxy materials based on maleimide chemistry. Polymer 53, 2320-2326 (2012).

39. Liu, J. Z., Lam, J. W. Y. \& Tang, B. Z. Acetylenic polymers: syntheses, structures, and functions. Chem. Rev. 109, 5799-5867 (2009).

40. Rostovtsev, V. V., Green, L. G., Fokin, V. V. \& Sharpless, K. A. stepwise Huisgen cycloaddition process: copper(I)-catalyzed regioselective "ligation" of azides and terminal alkynes. Angew. Chem. Int. Ed. 41, 2596-2599 (2002).

41. Tornøe, C. W., Christens, C. \& Meldal, M., Peptidotriazoles on solid phase: [1,2,3]-triazoles by regiospecific copper(I)-catalyzed 1,3-dipolar cycloadditions of terminal alkynes to azides. J. Org. Chem. 67, 3057-3064 (2002).

42. Qin, A. J., Lam, J. W. Y. \& Tang, B. Z. Click polymerization. Chem. Soc. Rev. 39, 2522-2544 (2010).

43. Qin, A. J., Lam, J. W. Y. \& Tang, B. Z. Click polymerization: progresses, challenges, and opportunities. Macromolecules 43, 8693-8702 (2010).

44. Qin, A. J. et al. Click polymerization: facile synthesis of functional poly(aroyltriazole)s by metal-free, regioselective 1,3-dipolar polycycloaddition. Macromolecules 40, 2308-2317 (2007).

45. Qin, A. J. et al. Metal-free click polymerization: synthesis and photonic properties of poly(aroyltriazole)s. Adv. Funct. Mater. 19, 1891-1900 (2009).

46. Li, H. K. et al. Metal-Free Click Polymerization of Propiolates and Azides: Facile Synthesis of Functional Poly(aroxycarbonyltriazole)s. Polym. Chem. 3, 1075-1083 (2012).

47. Wei, Q. et al. Efficient polymerization of azide and active internal alkynes. Macromol. Rapid Commun. 33, 1356-1361 (2012).

48. Gao, C. \& Yan, D. Y. Hyperbranched polymers: from synthesis to applications. Prog. Polym. Sci. 29, 183-275 (2004).

49. Banerjee, S., Komber, H., Häußler, L. \& Voit, B. Synthesis and characterization of hyperbranched poly(arylene ether)s from a new activated trifluoro $\mathrm{B}_{3}$ monomer adopting an $\mathrm{A}_{2}+\mathrm{B}_{3}$ approach. Macromol. Chem. Phys. 210, 1272-1282 (2009).

50. Gragert, M., Schunack, M. \& Binder, W. H. Azide/alkyne-“click"-reactions of encapsulated reagents: toward self-healing materials. Macromol. Rapid Commun. 32, 419-425 (2011)

51. Schunack, M., Gragert, M., Söhler, D., Michael, P. \& Binder, W. H. LowTemperature $\mathrm{Cu}(\mathrm{I})$-Catalyzed “Click” Reactions for Self-Healing Polymers Macromol. Chem. Phys. 213, 205-214 (2012).

52. Döhler, D., Michael, P. \& Binder, W. H. Autocatalysis in the Room Temperature Copper(I)-Catalyzed Alkyne-Azide "Click" Cycloaddition of Multivalent Poly(acrylate)s and Poly(isobutylene)s. Macromolecules 45, 3335-3345 (2012).

53. Sheng, X., Mauldin, T. C. \& Kessler, M. R. Kinetics of bulk azide/alkyne "click" polymerization. J. Polym. Sci. Part A: Polym. Chem. 48, 4093-4102 (2010).

54. Yuan, J. et al. Multi-responsive self-healing metallo-supramolecular gels based on "click" ligand. J. Mater. Chem. 22, 11515-11522 (2012).

55. Dong, H. C. et al. A new route to hyperbranched macromolecules: syntheses of photosensitive poly(aroylarylene)s via 1,3,5-regioselective polycyclotrimerization of bis(aroylacetylene)s. Macromolecules 38, 6382-6391 (2005).

56 . Wang, J. et al. Hyperbranched polytriazoles with high molecular compressibility: aggregation-induced emission and superamplified explosive detection. J. Mater. Chem. 21, 4056-4059 (2011).

\section{Acknowledgements}

We thank Mr. Guo H. for mechanical property measurements. The work reported in this paper was partially supported by the National Science Foundation of China (21222402, 
21174120, 20974028, 20974098, and 50703033), the key project of the Ministry of Science and Technology of China (2009CB623605), and the Research Grants Council of Hong Kong (603509, HKUST2/CRF/10, 604711, and N_HKUST620/11). B. Z. T. thanks the support from the Cao Guangbiao Foundation of Zhejiang University.

\section{Author contributions}

Q.W., A.J.Q. and B.Z.T. conceived and designed the experiments. Q.W. and J.W. conducted synthetic experiments. Q.W. performed the structure characterization, spectroscopic studies, and mechanical property measurements. X.S. took the photos. X.Z. and J.Z.S. helped with analysis of the data. Q.W., A.J.Q. and B.Z.T. wrote the manuscript.

\section{Additional information}

Supplementary information accompanies this paper at http://www.nature.com/ scientificreports

Competing financial interests: The authors declare no competing financial interests.

License: This work is licensed under a Creative Commons

Attribution-NonCommercial-ShareAlike 3.0 Unported License. To view a copy of this license, visit http://creativecommons.org/licenses/by-nc-sa/3.0/

How to cite this article: Wei, Q. et al. Self-healing hyperbranched poly(aroyltriazole)s. Sci. Rep. 3, 1093; DOI:10.1038/srep01093 (2013) 